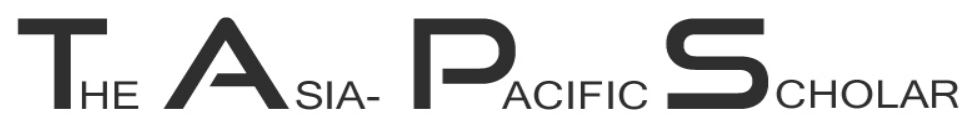 \\ MEDICAL AND HEALTH PROFESSIONS EDUCATION
}

\section{A two-edged sword: Narrative inquiry into Japanese doctors' intrinsic motivation}

\author{
Hiroshi Nishigori ${ }^{1}$, Tomio Suzuki ${ }^{2}$, Tomoko Matsui ${ }^{3}$, Jamiu Busari ${ }^{4}$ \& Tim \\ Dornan $^{5}$
}

${ }^{1}$ Centre for Medical Education, Nagoya University Graduate School of Medicine, Japan; ${ }^{2}$ Department of General Medicine, Osaka Medical College, Japan; ${ }^{3}$ Department of General Medicine, Nagoya University Graduate School of Medicine, Japan; ${ }^{4}$ Educational Development and Research Department, Faculty of Health, Medicine and Life Sciences, Maastricht University, The Netherlands; ${ }^{5}$ Centre for Medical Education, School of Medicine, Dentistry and Biomedical Sciences, Queen's University Belfast, United Kingdom

\begin{abstract}
Introduction: Although retaining a healthy and motivated medical workforce is becoming an intractable problem, the intrinsic motivation that keeps doctors working for patients remains under-investigated. The 2011 Tōhoku earthquake and tsunami provided a unique opportunity for culturally situated research into doctors' intrinsic motivation. The purpose of this study was to answer the research question: what motivates doctors to work for patients above and beyond expectations?

Methods: This paper reports a qualitative inquiry informed by semi-structured individual interviews with 15 Japanese doctors who had joined disaster relief activities, which uses the Bushido virtue code as a conceptual framework. The authors read transcripts repeatedly and conducted a cross-case analysis to identify final themes and illustrative narratives.

Results: A young doctor wanted to learn by testing out his capabilities. A senior doctor yearned to be of value to others. Other participants told how identifying with victims motivated them. There were negative as well as positive motivations, exemplified by a participant whose sense that well-educated people had a duty to help was coupled with a wish to avoid being blamed by others.

Discussion: Volunteering met participants' needs for self-esteem by restoring their relationships with patients to ones in which they had some measure of control. But avoiding being blamed or losing Meiyo (Honour) also motivated physicians to volunteer. Reinforcing the satisfaction of a job well done may help offset the lack of control, guilt, and shame that too easily results from the relentless pressures of workload and external accountability in today's healthcare systems.
\end{abstract}

Keywords: $\quad$ Burnout, Bushido, Guilt, Intrinsic Motivation, Narrative Inquiry, Professionalism, Self-esteem

\section{Practice Highlights}

- Motivation is a two-edged sword. It both makes doctors work above and beyond expectations and burns them out.

- We clarified five distinct narratives of motivation for doctors to work for patients above and beyond expectations: learning by testing out personal capabilities; being of value to others; identifying with victims; fulfilling 'the duty of the capable'; and feeling guilty or avoiding blame.

\section{INTRODUCTION}

Motivation is a two-edged sword. It both makes doctors work above and beyond expectations (Gillespie, Kelly, Duggan, \& Dornan, 2017) and burns them out (Dyrbye et al., 2014; Shanafelt, Bradley, Wipf, \& Back, 2002). Regulators have responded to high profile instances of unprofessional behaviour by imposing external motivators. These include mandatory continuing professional development, revalidation (Dornan, 2008), and rigorous investigation of alleged poor performance (General Medical Council, n.d.). Extrinsic motivators like these are necessarily negative because they prevent what doctors might do wrong rather than rewarding what doctors do right. Intrinsic motivation to care for patients brought many of today's doctors into medicine (Ratanawongsa, Howell, \& Wright, 2006). But now many of them are burning out and leaving medicine (Dyrbye et al., 2014; Lambert, Smith, \& Goldacre, 2018; 
Shanafelt et al., 2002). Perhaps the burden of practice becomes intolerable when extrinsic, negative motivators dominate over intrinsic, positive ones. A clearer understanding of doctors' intrinsic motivation could help retain a healthy medical workforce.

Motivation is defined as 'the psychological feature that arouses you to action toward a desired goal; the reason for the action; that which give purpose and direction to behaviour' (Princeton University, 2010). Researchers have investigated students' and doctors' motivation to learn using a number of psychological constructs. Achievement emotions motivate learners to higher levels of achievement (Artino, La Rochelle, \& Durning, 2010; McConnell \& Eva, 2012). Epistemic curiosity, selfdetermination, and self-efficacy motivate them to find answers to questions that arise from group discussion of clinical problems (Schmidt, 1993). Their motivation to work for patients has, however, been less thoroughly investigated than their motivation to learn. And more effort has been made to identify extrinsic than intrinsic motivators, particularly when it comes to retaining physicians in shortage specialties or underserved communities (Hancock, Steinbach, Nesbitt, Adler, \& Auerswald, 2009; Larkins \& Gupta, 2013; Rafiei, Arab, Rashidian, Mahmoudi, \& Rahimi-Movaghar, 2015; Verma et al., 2016). It has been more or less taken for granted, since Hippocrates, that doctors are intrinsically motivated to care selflessly for patients. Research has shown that interacting with patients, rising to the challenge of medicine, and helping patients motivates residents (Mennin, Kalishman, Friedman, Pathak, \& Snyder, 1996) but doctors' intrinsic motivation is still an under-researched topic (Ratanawongsa et al., 2006). We are, as a result, ill-prepared to address doctors' disillusionment.

One in two US residents (Dyrbye et al., 2014; Shanafelt et al., 2002) and a third of Japanese psychiatric trainees (Tateno et al., 2017) are reported to suffer burnout.
Situational causes include long working hours, sleep deprivation, excessive workload, and inadequate support from allied health professionals. Personal causes include family conflicts, isolation, and money problems. Professional causes include information overload and heavy responsibilities for patient care and the supervision of others (Levey, 2001). Efforts have been made to reduce the impact of these extrinsic causes by, for example, restricting duty hours and providing stress management workshops or teaching meditation (West, Dyrbye, Erwin, \& Shanafelt, 2016). These have not been uniformly effective (Busireddy et al., 2017). In the case of duty hours, research has shown how doctors' intrinsic motivation to care for and learn from patients can override their wish to sleep, in which case duty hours restrictions frustrate and demotivate them (Taylor, Nisker, \& Lingard, 2013; Taylor, Nisker, Teunissen, Dornan, \& Lingard, 2016). Maintaining a motivated, healthy, medical professional workforce is an intractable problem.

Differences in national cultures shed valuable light on medical professionalism (Helmich, Yeh, Kalet, \& AlEraky, 2017; Jha, Mclean, Gibbs, \& Sandars, 2015; Zaidi et al., 2016;). Japan is known for its strong, shared social values and positive work ethic (Wolf, 2013). It has a traditional value system known as Bushido, whose seven principle virtues are shown in Table 1: rectitude (gi), courage $(y u)$, benevolence (jin), politeness (rei), honesty (sei), honour (meiyo) and loyalty (chugi; Nishigori, Harrison, Busari, \& Dornan, 2014; Nitobe, 2012). Among these, rectitude (the way of thinking, deciding, and behaving in accordance with reason without wavering), benevolence (encompassing the concepts of love, sympathy, and pity for others), and loyalty (placing the group's needs above their own needs and interests) motivate doctors to work for others (Nishigori et al., 2014). Japan provides an appropriately rich cultural setting in which to research doctors' motivation.

\begin{tabular}{ll}
\hline$G i$ (Rectitude) & The way of thinking, deciding, and behaving in accordance with reason, without wavering it \\
\hline$Y u$ (Courage) & $\begin{array}{l}\text { The spirit of daring and bearing } \\
\text { Doing what is right in the face of danger }\end{array}$ \\
\hline Jin (Benevolence) & $\begin{array}{l}\text { Encompasses the concepts of love, sympathy, and pity for others } \\
\text { Recognised as the highest of all the attributes of the human soul } \\
\text { "Medicine is a benevolent art" }\end{array}$ \\
\hline Rei (Politeness) & Respectful regard for the feeling of others \\
\hline Sei (Honesty) & The Chinese character for honesty (sei) combines the characters for "word" and "perfect" \\
\hline Meiyo (Honor) & Recognised as the ultimate pursuit of goodness \\
\hline Chugi (Loyalty) & $\begin{array}{l}\text { Placing the group's needs above their own needs and interest } \\
\text { The interests of the family and the interests of its members are inseparable }\end{array}$ \\
\hline
\end{tabular}

Table 1. Seven virtues in Bushido

On March 11, 2011, an earthquake measuring 9.0 on the Richter scale (the most powerful ever recorded in Japan) and subsequent tsunami devastated the Tōhoku area.
This claimed more than 15,000 lives and caused damage to the Fukushima Daiichi Nuclear Power Plant stations, which was one of the greatest nuclear disasters in history. 
Health workers from all over (and outside) Japan volunteered in great numbers to support victims of the disaster at potential personal cost (Ministry of Health, Labour and Welfare, 2012). This behaviour was recognised within Japan as being motivated by Bushido values (Mochizuki, Sakamoto, \& Henmi, 2016). The earthquake and tsunami, then, were an 'experiment of nature' which provided a unique opportunity to explore doctors' intrinsic motivation in the context of twentyfirst century medicine (Dickerson, 2012). The purpose of this study was to answer the following research question: what motivates doctors to work for patients above and beyond expectations?

\section{METHODS}

\section{A. Ethical Approval}

Ethical approval for all aspects of this study on all sites was granted by the Institutional Review Board at the two lead institutions - the University of Tokyo and Nagoya University Hospital.

\section{B. Setting}

After the earthquake and tsunami, more than 12,000 healthcare professionals in more than 2,500 teams went to the Tohoku region and provided medical support in devastated areas (Ministry of Health, Labour and Welfare, 2012). The teams included ones from the University of Tokyo Hospital (UOTH), Saku Central Hospital of the Nagano Prefectural Federation of Agricultural Cooperatives for Health and Welfare (SAKU), the Primary Care for All Team (PCAT) of the Japan Primary Care Association (JPCA), and from Nagoya University Hospital (NUH). We recruited participants to this study from all four of those teams.

\section{Methodology}

We chose narrative inquiry as our methodology because we wanted to explore the human meaning of doctors' motivations as expressed in their own words (Clandinin, Cave, \& Berendonk, 2017). This was particularly appropriate in a country with such a strong narrative tradition as Japan, where Murasaki Shikibu wrote the world's first novel in the 11th century - "The Tale of Genji" (Shikibu, 2006) - and there is a centuries-old tradition of developing so-called Katarimono narratives (Randel, 2003). Narrative inquiry, originating in hermeneutics and phenomenology, is a qualitative research methodology widely used in history, anthropology, and sociology (Bleakley, 2005; Liamputtong, 2013). It is 'a way of inquiring into experience that attends to individuals' lives but remains attentive to the larger context and relationships within which lives are nested' (Clandinin et al., 2017). It generates data in the form of stories, interprets those stories, and represents them in narrative form (Schwandt, 1997). Through thinking not 'about' but 'with' stories, 'it strives to preserve the complexity of what it means to be human and to locate these observations of people and phenomena in society, history and time' (Bleakley, 2005; Josselson, 2006). Relying on the foundational work of philosophers such as Ricoeur, Heidegger, and Husserl (Wertz et al., 2011), narrative inquiry respects a multiplicity of ways of being in the world and the relative nature of truth (Clandinin, 2006). Consistent with this methodological choice, we took a constructivist stance towards the research.

\section{Recruitment, Participants, and Data Collection}

HN, TS and TM - Japanese general internists, who worked in three health provider organisations named above and teach professionalism - recruited and interviewed participants. One of them (HN) had participated in the Tōhoku disaster relief activities. They used a combination of face-to-face and email communication to invite doctors in organisations that had joined disaster relief activities to participate in the study. $\mathrm{HN}$ recruited four participants from the 117 doctors in UOTH who had contributed. TM recruited four participants from the 27 doctors in SAKU who had contributed. TS recruited two participants from the 66 doctors in NUH who had contributed. And, finally, HN and TM, who were members of the JPCA, asked members who had supported victims of the earthquake, of whom five agreed.

After being assured of anonymity and data security, participants gave written informed consent. Between May 2011 and April 2012, we conducted semi-structured individual interviews in the Japanese language with the 15 participants, whose attributes are shown in Table 2. They gave rich, individual accounts, which we judged to provide a sufficient sample for narrative analysis.

The main interview prompts were; 1) "Tell me what your disaster relief activities were like", and 2) "Why did you provide medical support in Tōhoku?" The first (HN), second (TS), and third (TM) authors interviewed four, two, and 11 participants respectively (HN and TM interviewed two doctors together). They conducted the interviews, which lasted 30 to $90 \mathrm{~min}$, in locations convenient to interviewees (e.g. in a university meeting room or cafe near a train station).

\section{E. Data Analysis}

The interviews were audio-recorded and transcribed verbatim immediately afterwards. Subsequently, all three interviewers read transcripts of the interviews they had conducted and performed a preliminary analysis of 
themes in participants' narratives (stage 1; Riessman, 2007). Then the first author (HN) read all the transcripts repeatedly, identified themes, and chose an informative set of narratives (stage 2) as defined by these criteria:

1. Described participants' motivation to support earthquake victims.

2. Narrated a participant's individual motivation rather than a general one.

3. Was associated with the virtues of Bushido, especially rectitude ( $\mathrm{Gi})$, benevolence ( $\mathrm{Jin})$, and loyalty (Chugi).
$\mathrm{HN}$ translated them into English language at this stage (stage 3) and then conducted a cross-case analysis to identify patterns, which overarched individual narratives (stage 4; Wertz et al., 2011). Then JB and TD (medical doctors and education researchers from two other countries) joined $\mathrm{HN}$ in discussing the findings, deconstructing, and reconstructing them (stage 5). The final text with themes and illustrative narratives presented in Results was agreed among the five authors (stage 6).

\begin{tabular}{|c|c|c|c|c|c|c|}
\hline Doctor & $\begin{array}{c}\text { Postgraduate } \\
\text { Year }\end{array}$ & Organisation* & Interviewer(s)** & $\begin{array}{c}\text { Interview } \\
\text { Month/Year }\end{array}$ & Sex & Specialty \\
\hline A & 10 & UOTH & $\mathrm{HN}$ & $05 / 2011$ & Female & Nephrology \\
\hline $\mathrm{B}$ & 2 & SAKU & $\mathrm{HN} \& \mathrm{TM}$ & 08/2011 & Male & Junior Resident \\
\hline $\mathrm{C}$ & 2 & SAKU & $\mathrm{TM}$ & $09 / 2011$ & Male & Junior Resident \\
\hline $\mathrm{D}$ & 3 & SAKU & $\mathrm{TM}$ & $09 / 2011$ & Male & Senior Resident (General Practice) \\
\hline $\mathrm{E}$ & 23 & UOTH & $\mathrm{HN} \& \mathrm{TM}$ & $10 / 2011$ & Male & Nephrology \\
\hline $\mathrm{F}$ & 18 & UOTH & $\mathrm{HN}$ & $10 / 2011$ & Male & Nephrology \\
\hline G & 11 & PCAT & $\mathrm{TM}$ & $10 / 2011$ & Male & General Practice \\
\hline $\mathrm{H}$ & 10 & PCAT & $\mathrm{TM}$ & $11 / 2011$ & Female & Psychosomatic Internal Medicine \\
\hline I & 7 & PCAT & $\mathrm{TM}$ & $11 / 2011$ & Male & General Practice \\
\hline $\mathrm{J}$ & 11 & UOTH & $\mathrm{TM}$ & $01 / 2012$ & Male & Cardiology \\
\hline K & 6 & PCAT & $\mathrm{TM}$ & $02 / 2012$ & Male & General Practice \\
\hline $\mathrm{L}$ & 4 & SAKU & $\mathrm{TM}$ & $02 / 2012$ & Male & Senior Resident (General Practice) \\
\hline M & 4 & PCAT & $\mathrm{TM}$ & 03/2012 & Male & Senior Resident (General Practice) \\
\hline $\mathrm{N}$ & 18 & NUH & TS & $04 / 2012$ & Male & Nephrology \\
\hline $\mathrm{O}$ & 12 & NUH & TS & $04 / 2012$ & Male & Geriatrics \\
\hline \multicolumn{7}{|c|}{$\begin{array}{l}\text { Note: *Organisation: UOTH-The University of Tokyo Hospital, } \\
\text { SAKU-Saku Central Hospital of the Nagano Prefectural Federation of } \\
\text { Agricultural Cooperatives for Health and Welfare, } \\
\text { PCAT-Primary Care for All Team by the Japan Primary Care Association, } \\
\text { NUH-Nagoya University Hospital } \\
\text { Interviewer: HN-Hiroshi Nishigori, TM-Tomoko Matsui, TS-Tomio Suzuki }\end{array}$} \\
\hline
\end{tabular}

\section{F. Reflexivity}

Careful attention was paid to the positioning of and relationship between researchers and narrators (Wertz et al., 2011). While collecting the data and analysing them, HN, TM and TS met regularly, discussed, and reflected on their interpretation. They are both deeply versed in Bushido and used this perspective, reflexively, to inform the selection and interpretation of narratives. They recognised how their positions and values as medical doctors and educators influenced the data analysis; for example, they tended to regard disaster-relief activities as 'good' or 'desired'. When they observed preconceptions of that sort in one another's interpretations, they drew attention to them. The two non-Japanese authors (JB and TD) helped $\mathrm{HN}$ be critically reflexive and explain how their understanding of Bushido informed the analysis.

\section{RESULTS}

There were five distinct narratives of motivation: learning by testing out personal capabilities; being of value to others; identifying with victims; fulfilling 'the duty of the capable'; and feeling guilty or avoiding blame. We illustrate them with representative narratives.

Participants were so motivated to support victims that they competed to be team members. One doctor was very disappointed when she was not chosen as a rescue team member.

"[When I applied], I really really wanted to be selected as a team member. However, I turned out to fail... I struggled to find another way [to go to rescue people in Tōhoku]... Though lots of other doctors were also applying to be rescue team members..."

(Doctor $A)$

Another wanted to provide medical support despite having delivered her baby just before the earthquake occurred.

"At first, I gave up participating in a rescue team because at that time I was taking care of my baby. [So I thought I was not able to go] At least until stopping 
breast-feeding. So I really envied my colleagues [who were able to visit Tōhoku], when they reported their rescuing activities."

(Doctor H)

\section{A. Learning by Testing out Personal Capabilities}

A positive motivation, particularly for younger doctors, was to find what they were capable of under exceptional circumstances. One participant used these words to explain how disaster relief challenged his personal capabilities:

"On this particular occasion, my involvement in disaster-relief activities was a rare and unusual opportunity to experience something that existed on a higher level... I am sorry to tell you that I went there not to rescue the victims... To be honest, I would like to find out how much I can do."

(Doctor C)

Another young doctor expressed this positive motivation in terms of curiosity and an opportunity to enhance his clinical competencies.

"I think I went there out of my curiosity... I thought I could gain [various] experiences by visiting Tōhoku area to rescue people... Because I am still a senior resident, I tend to make an appeal, saying, "I can do this sort of thing" or "I acquired that sort of thing". And I thought that [appeal] was really positive, not negative. This style may be different from that of senior doctors."

(Doctor M)

\section{B. Being of Value to Others}

This is exemplified by the narrative of a senior doctor, who found the defensive style of clinical practice within the current Japanese healthcare system demotivating. Going to support victims of the disaster relieved the sense of stagnation he had in everyday work settings. His yearning for a sense of being of value to others motivated him to go to Tōhoku.

"In my daily clinical practice, the top priority is to avoid making any trouble and manage risk. It was totally different when I was a young resident. At that time, the more I worked for my patients, the more (positive) responses I had got from them... In this sense [as an opportunity to be thanked by patients], I was $100 \%$ positive about the idea of going [to the disaster zone] ... Such an experience is very rare in our daily clinical activities as healthcare professionals. This could be a motive [for my decision to go to the disaster-struck area]."

(Doctor N)
Another mid-career doctor told how sacrificing himself in order to be of value to others was one of his virtues.

"When I was a high school student, I started thinking of becoming a doctor... Then, after I became a medical student, I believed that self-sacrifice was great."

(Doctor M)

\section{Identifying with Victims}

Doctors who had links with the Tōhoku area (for example, those who had been medical students there) were motivated to participate in disaster-relief activities by a sense of identification with Tōhoku. One junior doctor who had graduated from Tōhoku University two years earlier went to rescue victims because his classmates were doing so in areas that he was emotionally attached to.

"I had a special feeling for many of the disaster-struck areas. In addition, about 60 to $70 \%$ of my classmates remained in the region, some of who were working at the Japanese Red Cross Ishinomaki Hospital, the Ishinomaki Municipal Hospital, or [hospitals located in] Kesennuma [which were the hub medical institutions around the affected areas] ... I was given information on what they were doing [rescuing victims] through Twitter. So I also wanted to do something, which was the biggest motivation..."

(Doctor B)

Another senior doctor who had been to the Tōhoku area several times was motivated by physically feeling the shock-waves in Tokyo.

"Having such a disaster in a nearby location is certainly very different from hearing the news of the earthquake in Haiti [happened in 2010], for example... Even though the value of life does not differ, these two cases are entirely different in terms of their emotional impact [on myself]. [This time, also] At the University of Tokyo, I myself experienced the fierce shaking and many of my colleagues could not return to their homes [because almost all the trains in Tokyo were shut down]. Besides that, some distance away from us, towns I have visited quite a few times in the past were washed away by tsunamis. These invoked a great sense of being close, which, it seems, served as great motivation for me."

(Doctor E)

\section{Fulfilling 'The Duty of the Capable'}

A mid-career female doctor specialising in psychosomatic internal medicine felt obliged to provide medical support because she was competent to do so. 
"[When we had the Great Hanshin Earthquake in 1995], I was just a first-year medical student... And many argued for the importance of mental healthcare. I got involved in volunteer activity, but I couldn't do anything [related to mental healthcare] because I was incompetent, so I felt chagrined... On the other hand, [at the time of Tóhoku earthquake] I'd become a doctor, and had been working as an internist specialising in psychosomatic medicine for a long time. I knew I had expertise [to support people who needed mental healthcare]. So, to me, there's no way that I wouldn't go [to rescue victims]."

(Doctor H)

Another senior male doctor who was working at a prestigious Japanese university was driven by his sense that competent or well-educated people had a duty to help.

"To describe my motive in a positive manner, I would say that I had to repay society for the education I had received and the benefits I had enjoyed as a result of that education... It [disaster-relief activity] seemed really tough, but I wanted to go there. In addition, because I have two children, I wanted to show myself behaving honourably to them... I didn't want to regret not having been there [as a rescue team member]. Also, as I was already not young, I thought I could not take the next opportunity [to go to affected areas to rescue victims of disaster].”

(Doctor E)

\section{E. Feeling Guilty or Avoiding Blame}

Doctor E-see immediately preceding-had a negative as well as a positive motivation. He wanted to avoid being blamed by others:

"To describe my motive in a negative manner, I would say that I did not want to be condemned for remaining inactive in spite of my capability to help or being degenerate. In reality, my motive was a combination of the two [the positive one and the negative one]."

(Doctor E)

A senior resident described how the atmosphere of his institution compelled residents to contribute to rescue efforts. Like Doctor E, he went to support victims to shake off feelings of guilt he would have had if he had done nothing.

"Excuse me if I am using improper terms, but there was a mood that condemned non-participating residents [those who did not volunteer to participate in the disaster-relief activities] as being unpatriotic. So I felt I had to respond to the message board [where many residents in Saku Central Hospital wrote on disasterrelief activities] and show my willingness to go [to Tōhoku]. This was my honest feeling... I thought it was too much of a bother. But I was told to be a member for real. I felt it was like a draft notice [when I received the order]. I felt I was being told to go to the front..."

(Doctor D)

\section{DISCUSSION \& CONCLUSION}

Narrative accounts of participants' responses to appalling human suffering caused by the Tōhoku earthquake and tsunami elucidated physicians' intrinsic motivations to work about and beyond expectations. There were several motivations. One was that disaster relief freed participants from the constraints of their normal working lives. It allowed residents to test their limits and perform beyond them. It allowed senior physicians to be of value to others, unconstrained by fear of litigation. Another motivation was identifying with victims. Physicians rescued sufferers because they were socially connected to the affected area. Another motivation was feeling morally obliged to help victims. The final motivating force is a particularly telling one. Whilst the preceding ones 'pulled' participants to volunteer, guilt and fear of blame evoked by an excessive sense of duty 'pushed' them to do so. Even outside their usual working situations, some participants were poised between positive and negative motivations.

The analogy between Bushido and the guilt and fear of blame evoked by participants' excessive sense of duty makes the final motivating force a telling one. To avoid blame and preserve Meiyo (Honour), ancient Samurai performed 'Seppuku', ritual suicide by disembowelment (Nitobe, 2012). Being blamed or losing Meiyo (Honour) may constitute 'Haji (shame)' in Japan (Benedict, 2006). Being seized by shame may have motivated doctors to support victims but it might also explain why doctors burn out. Individual psychology suggests we should warn doctors against self-destructive behaviour rather than condone it anticipated (Adler, 2010). One motivation to work for patients above and beyond expectations is wanting to be superior to, or even control other people (Singh, 1991). The earthquake created conditions where doctors were de facto superior to patients. This may have improved participants' psychological health by meeting 'esteem needs' that were unmet in today's practice (Shergill, 2010). These unmet esteem needs, we suggest, may take a psychological toll that results in doctors' burnout, dropout, and worse.

An original feature of this study was its use of Bushido as a theoretical framework. We purposively sampled the 
Japanese culture because it reconciles personal with communal values in informative ways (Cruess, Cruess, \& Steinert, 2010; Ho, Yu, Hirsh, Huang, \& Yang, 2011) but this also limits the transferability of our findings. Whilst doctors in any culture might seize opportunities to learn new skills, motivation to escape from the litigious climate of contemporary practice may be greater in developed than developing countries. Another limitation to the transferability of this research is that Bushido (Nitobe, 2012), which is embedded in the Japanese culture, is a virtue ethics code. Among its seven virtues, Chugi (Loyalty) was apparent in participants' wish to help is a feature of victims with whom they identified. The moral imperative for people with wealth, power, and prestige to help less fortunate people reflects the Bushido virtues of $G i$ (Rectitude) and Jin (Benevolence). We cannot assume these virtues transfer to all cultures, though there are parallels with the European code of 'noblesse oblige'. Further studies in Asia and beyond using specific cultural lenses could clarify the wider applicability of our findings. Whilst the transferability of narrative inquiry to other cultures is also uncertain, this study provides evidence of its usefulness. Perhaps the greatest limitation of this research is that it was better able to clarify participants' intrinsic motivations than their personal sacrifices. We surmise that rescuing earthquake victims was at a cost to their private lives and home institutions but our data give limited insight into the personal cost of participants' usual practice.

We propose two themes for further research: 1) doctors' guilty feelings, and 2) their esteem needs. We suggest that the first should be explored alongside their propensity to burnout and stress, workloads and motivation. Regarding the second, application of individual psychology to future research could give valuable insight into how doctors' motivation stems from their needs for esteem. We hypothesise that such needs arise from the competitive nature of, for example, gaining entry to medical school. It is paradoxical that competing successfully should motivate doctors to care for others. It is plausible, though, because a competitive spirit might fuel doctors' esteem needs and lead them to earn admiration from such vulnerable people as earthquake victims.

One implication for educational practice is that medical educators could use doctors' narratives as a tool to help medical students and residents learn about altruism in medical professionalism. Our findings suggest that doctors from different generations and cultures could usefully explore similarities and differences in their work values and the core values of medicine that underlie them. Finally, we suggest that medical educators who cultivate doctors' professionalism should think of doctors' intrinsic motivation to work as a two-edged sword. It can promote altruism, but it can also be evoked by hurtful feelings of guilt that lead to burnout.

Motivation is a two-edged sword. It both makes doctors work above and beyond expectations and burns them out.

\section{Notes on Contributors}

Hiroshi Nishigori is a Professor, at the Center for Medical Education, Nagoya University Graduate School of Medicine, Japan.

Tomio Suzuki is a Professor, at the Department of General Medicine, Osaka Medical College, Japan.

Tomoko Matsui is a PhD candidate, at the Department of General Medicine, Nagoya University Graduate School of Medicine, Japan.

Jamiu Busari is an Associate Professor, at the Educational Development and Research Department, Faculty of Health, Medicine and Life Sciences, Maastricht University, The Netherlands.

Tim Dornan is a Professor, at the Centre for Medical Education, School of Medicine, Dentistry and Biomedical Sciences, Queen's University Belfast, UK.

\section{Ethical Approval}

Ethical approval for all aspects of this study on all sites was granted by the Institutional Review Board at the two lead institutions - the University of Tokyo and Nagoya University Hospital.

\section{Acknowledgements}

The authors wish to offer their sincere condolences for those who lost their lives in the 2011 Tōhoku earthquake and tsunami. The authors wish to thank all the study participants for contributing to this work.

\section{Funding}

This research was supported through a Grand-in-Aid for Scientific Research (KAKENHI), \#15H04750, by Japan Society for the Promotion of Science.

\section{Declaration of Interest}

The authors declare no conflict of interest. 


\section{References}

Adler, A. (2010). What life should mean to you. Eastford, CT: Martino Fine Books.

Artino, A. R., La Rochelle, J. S., \& Durning, S. J. (2010). Secondyear medical students' motivational beliefs, emotions, and achievement. Medical Education, 44(12), 1203-1212.

Benedict, R. (2006). The chrysanthemum and the sword: Patterns of Japanese culture. Boston, MA: Houghton Mifflin Harcourt.

Bleakley, A. (2005). Stories as data, data as stories: Making sense of narrative inquiry in clinical education. Medical Education, 39(5), 534-540.

Busireddy, K. R., Miller, J. A., Ellison, K., Ren, V., Qayyum, R., \& Panda, M. (2017). Efficacy of interventions to reduce resident physician burnout: A systematic review. Journal of Graduate Medical Education, 9(3), 294-301.

Clandinin, D. J. (2006). Handbook of narrative inquiry: Mapping a methodology. London, England: SAGE Publications, Inc.

Clandinin, D. J., Cave, M. T., \& Berendonk, C. (2017). Narrative inquiry: A relational research methodology for medical education. Medical Education, 51(1), 89-96.

Cruess, S. R., Cruess, R. L., \& Steinert, Y. (2010). Linking the teaching of professionalism to the social contract: A call for cultural humility. Medical Teacher, 32(5), 357-359.

Dickerson, P. (2012). Social psychology: Traditional and critical perspectives. Essex, England: Pearson Education Limited.

Dornan, T. (2008). Self-assessment in CPD: Lessons from the UK undergraduate and postgraduate education domains. The Journal of Continuing Education of Health Professions, 28(1), 32-37.

Dyrbye, L. N., West, C. P., Satele, D., Boone, S., Tan, L., Sloan, J., \& Shanafelt, T. D. (2014). Burnout among U.S. medical students, residents, and early career physicians relative to the general U.S. population. Academic Medicine, 89(3), 443-451.

General Medical Council. (n.d.). Performance assessments. Retrieved from https://www.gmc-uk.org/concerns/doctors_under_ investigation/performance assessments.asp

Gillespie, H., Kelly, M., Duggan, S., \& Dornan, T. (2017). How do patients experience caring? Scoping review. Patient Education and Counseling, 100(9), 1622-1633.

Hancock, C., Steinbach, A., Nesbitt, T. S., Adler, S. R., \& Auerswald, C. L. (2009). Why doctors choose small towns: A developmental model of rural physician recruitment and retention. Social Science \& Medicine, 69(9), 1368-1376.

Helmich, E., Yeh, H. M., Kalet, A., \& Al-Eraky, M. (2017). Becoming a doctor in different cultures: Toward a cross-cultural approach to supporting professional identity formation in medicine. Academic Medicine, 92(1), 58-62.

Ho, M. J., Yu, K. H., Hirsh, D., Huang, T. S., \& Yang, P. C. (2011). Does one size fit all? Building a framework for medical professionalism. Academic Medicine, 86(11), 1407-1414.

Jha, V., Mclean, M., Gibbs, T. J., \& Sandars, J. (2015). Medical professionalism across cultures: A challenge for medicine and medical education. Medical Teacher, 37(1), 74-80.

Josselson, R. (2006). Narrative research and the challenge of accumulating knowledge. Narrative Inquiry, 16(1), 3-10.
Lambert, T. W., Smith, F., \& Goldacre, M. J. (2018). Why doctors consider leaving UK medicine: Qualitative analysis of comments from questionnaire surveys three years after graduation. Journal of the Royal Society of Medicine, 111(1), 18-30.

Larkins, M. S., \& Gupta, T. S. (2013). Recruitment and retention of general practitioners in rural Canada and Australia: A review of the literature. Canadian Journal of Rural Medicine, 18(1), 13-23.

Levey, R. E. (2001). Sources of stress for residents and recommendations for programs to assist them. Academic Medicine, $76(2), 142-150$

Liamputtong, P. (2013). Research methods in health. South Melbourne, Australia: Oxford University Press Australia \& New Zealand.

McConnell, M. M., \& Eva, K. W. (2012). The role of emotion in the learning and transfer of clinical skills and knowledge. Academic Medicine, 87(10), 1316-1322.

Mennin, S. P., Kalishman, S., Friedman, M., Pathak, D., \& Snyder, J. (1996). A survey of graduates in practice from the University of New Mexico's conventional and community-oriented, problembased tracks. Academic Medicine, 71(10), 1079-1089.

Ministry of Health, Labour and Welfare. (2012). 東日本大震災へ の医療面での対応について [Respond to the 2011 Tōhoku earthquake and tsunami]. Retrieved from http://www.bousai.go.jp/ kaigirep/kentokai/tamokutekisen/3/pdf/shiryou1.pdf

Mochizuki, I., Sakamoto, S., \& Henmi, K. (2016, June). 医療人の あるべき姿 [What healthcare professions should be]. Paper presented at the $66^{\text {th }}$ Congress of Japan Hospital Association, Iwate.

Nishigori, H., Harrison, R., Busari, J., \& Dornan, T. (2014). Bushido and medical professionalism in Japan. Academic Medicine, 89(4), 560-563.

Nitobe, I. (2012). Bushido: The soul of Japan. New York, NY: Kodansha International.

Princeton University. (2010). WordNet Search - 3.1 [Word search results]. Retrieved from http://wordnetweb.princeton.edu/perl/ webwn?s=motivation

Rafiei, S., Arab, M., Rashidian, A., Mahmoudi, M., \& RahimiMovaghar, V. (2015). Factors influencing neurosurgeons' decision to retain in a work location: A qualitative study. Global Journal of Health Science, 7(5), 333-351.

Randel, D. M. (2003). The Harvard dictionary of music. Boston, MA: The Belknap Press of Harvard University Press.

Ratanawongsa, N., Howell, E. E., \& Wright, S. M. (2006). What motivates physicians throughout their careers in medicine? Comprehensive Therapy, 32(4), 210-217.

Riessman, C. K. (2007). Narrative methods for the human sciences. London, England: SAGE Publications, Inc.

Schmidt, H. G. (1993). Foundation of problem-based learning Some explanatory notes. Medical Education, 27(5), 422-432.

Schwandt, T. A. (1997). Qualitative inquiry: A dictionary of terms. London, England: SAGE Publications, Inc.

Shanafelt, T. D., Bradley, K. A., Wipf, J. E., \& Back, A. L. (2002) Burnout and self-reported patient care in an internal medicine residency program. Annals of Internal Medicine, 136(5), 358-367.

Shergill, H. K. (2010). Psychology. Delhi, India: PHI Learning. 
Shikibu, M. (2006). The tale of Genji. New York, NY: Penguin Classics.

Singh, A. K. (1991). The comprehensive history of psychology. New Delhi, India: Motilal Banarsidass.

Tateno, M., Jovanović, N., Beezhold, J., Uehara-Aoyama, K., Umene-Nakano, W., Nakamae, T., ... Kato, T. A. (2017). Suicidal ideation and burnout among psychiatric trainees in Japan. Early Intervention in Psychiatry, 12(5), 935-937.

Taylor, T. S., Nisker, J., \& Lingard, L. (2013). To stay or not to stay? A grounded theory study of residents' postcall behaviors and their rationalizations for those behaviors. Academic Medicine, $88(10), 1529-1533$

Taylor, T. S., Nisker, J., Teunissen, P. W., Dornan, T., \& Lingard, L. (2016). Recovery of sleep or recovery of self? A grounded theory study of residents' decision making regarding how to spend their nonclinical postcall time. Academic Medicine, 91(3), 395-400.

Verma, P., Ford, J. A., Stuart, A., Howe, A., Everington, S., \& Steel, N. (2016). A systematic review of strategies to recruit and retain primary care doctors. BMC Health Services Research, 16(1), 126.
Wertz, F. J., Charmaz, K., McMullen, L. M., Josselson, R., Anderson, R., \& McSpadden, E. (2011). Five ways of doing qualitative analysis: Phenomenological psychology, grounded theory, discourse analysis, narrative research, and intuitive inquiry. New York, NY: Guilford Press.

West, C. P., Dyrbye, L. N., Erwin, P. J., \& Shanafelt, T. D. (2016). Interventions to prevent and reduce physician burnout: A systematic review and meta-analysis. The Lancet, 388(10057), 2272-2281.

Wolf, R. (2013). Management relations in the work culture in Japan as compared to that of the West. Innovative Journal of Business and Management, 2(5), 116-122.

Zaidi, Z., Verstegen, D., Vyas, R., Hamed, O., Dornan, T., \& Morahan, P. (2016). Cultural hegemony? Educators' perspectives on facilitating cross-cultural dialogue. Medical Education Online, $21(1), 33145$

*Hiroshi Nishigori

Centre for Medical Education,

Nagoya University Graduate School of Medicine,

65 Tsurumai-cho, Showa-ku, Nagoya 466-8550, Japan

Tel: +81-52-744-2997

Email: hiroshi.nishigori@gmail.com 